\title{
Ultrastructure of the Infectious and Reproductive Forms of Holospora obtusa, a Bacterium Infecting the Macronucleus of Paramecium caudatum
}

\author{
By HANS-DIETER GÖRTZ, ${ }^{*}$ NORBERT AHLERS ${ }^{2}$ \\ AND HORST ROBENEK ${ }^{2}$ \\ ${ }^{1}$ Zoological Institute, ${ }^{2}$ Cell Biology Group, Faculty of Medicine, University of Münster, \\ D-4400 Münster, Federal Republic of Germany
}

(Received 17 March 1989; revised 28 June 1989; accepted 27 July 1989)

The ultrastructure of the infectious and reproductive forms of Holospora obtusa, a bacterium colonizing the macronucleus of Paramecium caudatum, was analysed with the aid of ultrathin sections, freeze-fracture, freeze-etching and cytochemical electron microscopical techniques. The infectious form differed considerably from the reproductive form. The bacterial cytoplasm of the infectious form was confined to less than half of the cell, the rest being occupied by a voluminous periplasmic space. The periplasmic space contained a highly osmiophilic fine granular material. At the end of the cell distal from the cytoplasm, a tip containing less osmiophilic fine granular material was observed. Freeze-fracture and freeze-etching studies revealed differences in the patterns of intramembranous particles between the two forms. It is suggested that some of the structures characterizing the infectious form have a function in the infection process.

\section{INTRODUCTION}

The mechanism of invasion of eukaryotic cells by bacteria is not understood in most cases. In particular, little is known about how bacteria may leave a phagosome after being phagocytosed and how they are eventually transported to the nuclei or other compartments of the host cells. Some bacteria develop special infectious forms, e.g. the initial bodies of Chlamydia (Moulder, 1984), and it must be assumed that the infectious forms have special signals necessary for recognition by the host cell.

Holospora obtusa infects the macronucleus of Paramecium caudatum (Protista, Ciliata). The bacteria of the genus Holospora show a developmental cycle with reproductive and infectious forms (for reviews see Preer \& Preer, 1984; Görtz, 1986). In the host nucleus the reproductive (vegetative) form multiplies by binary division, whereas the infectious form does not divide. During division of the host nucleus the reproductive forms enter the daughter nuclei. The infectious forms, however, remain in the connecting piece of the dividing nucleus and are released from the host cell after its division. Only the infectious forms are able to infect other paramecia, where they leave the phagosomes and enter the nuclei (Ossipov et al., 1975; Görtz \& Wiemann, 1989).

Fine structural features of $H$. obtusa have been reported (Gromov et al., 1976; Görtz, 1983). After a description of the infection process by Görtz \& Wiemann (1989) and initial biochemical investigations on these bacteria (Görtz et al., 1988) a more complete analysis became necessary. In the present work, the ultrastructure of the reproductive and infectious forms of $H$. obtusa was studied by means of various electron microscopic methods.

\section{METHODS}

Organisms. Paramecium caudatum (strain ATCC 50009) infected with Holospora obtusa was grown in a Cerophyl medium (Görtz \& Dieckmann, 1980) inoculated with Enterobacter aerogenes as a food organism.

Abbreviations: IF, infectious form; IMPs, intramembrane particles; RF, reproductive form. 
Thin-section electron microscopy. Cells were fixed for $30 \mathrm{~min}$ with $2.5 \%(\mathrm{v} / \mathrm{v})$ glutaraldehyde in $0.01 \mathrm{M}$-PIPES buffer $\mathrm{pH} 7 \cdot 2$, postfixed with $1 \%(\mathrm{w} / \mathrm{v}) \mathrm{OsO}_{4}$, dehydrated with ethanol and embedded in Epon 812 . Thin sections were stained with lead citrate and uranyl acetate.

Freeze-fracture electron microscopy. Either paramecia infected with bacteria, or bacteria isolated from the nuclei of paramecia and concentrated on a Percoll (Pharmacia) gradient (Schmidt et al., 1987), were studied. Probes with concentrated cells of a culture $(100 \mathrm{ml})$ were fixed with $3 \%$ glutaraldehyde in $0.01 \mathrm{M}$-PIPES-buffer pH 7.2. Prefixed cells were washed and treated for at least $2 \mathrm{~h}$ with $30 \%(\mathrm{v} / \mathrm{v})$ glycerol in distilled water. Samples were frozen in Freon 22 at $-156^{\circ} \mathrm{C}$ and immediately transferred into liquid nitrogen $\left(-196^{\circ} \mathrm{C}\right)$. Replicas were made according to standard techniques on a Balzers BA 300 freeze-fracture apparatus (Balzers AG, Liechtenstein) equipped with electron gun evaporators and a quartz crystal thickness monitor. The fracture faces were coated with platinum/carbon at an angle of $45^{\circ}$ followed by carbon at $90^{\circ}$. The replicas were cleaned overnight in household bleach and washed in distilled water. They were picked up on 200 mesh copper grids and examined in a Philips EM 301 electron microscope at $60 \mathrm{kV}$.

Freeze-etching electron microscopy. For freeze-etching the fixed samples were transferred into distilled water and then frozen and fractured as described above. The probes were fractured as described above. Subsequently, the temperature of the probe was raised from $-100^{\circ} \mathrm{C}$ to $-90^{\circ} \mathrm{C}$ for $3 \mathrm{~min}$. The faces were then shadowed with platinum/carbon as described above.

Cytochemistry with RNAase-gold. Colloidal gold was prepared following the method of Frens (1973) and coupled to RNAase A (Sigma) as described by Bendayan (1984). Cells were fixed with glutaraldehyde as described above but were not postfixed with $\mathrm{OsO}_{4}$. Thin sections were rinsed with phosphate-buffered saline (PBS; 0.01 M, pH 7.2) containing polyethylene glycol $\left(0.02 \% M_{\mathrm{r}} 20000\right)$ and pretreated with $3 \%(\mathrm{w} / \mathrm{v})$ bovine serum albumin. The sections were then incubated with RNAase-gold, rinsed with buffer (three times) and stained with uranyl acetate and lead citrate.

\section{RESULTS}

\section{Thin-section electron microscopy}

Infected macronuclei contain up to several hundred cells of $H$. obtusa. The ratio of reproductive (RF) and infectious forms (IF) differs depending on the physiological conditions of the host cell (Ossipov et al., 1975; Görtz, 1983), but both forms (and intermediate forms; not shown) are present simultaneously. The two forms could easily be distinguished by their different cytology. In thin sections of the RF, ribosomes and floccular material appeared evenly distributed throughout the cytoplasm. The cytoplasm was surrounded by two membranes with a thin dark layer between them, resembling various Gram-negative bacteria, However, the inner membrane was hardly visible in conventional thin sections (Fig. 1). Proof for the location of the inner membrane came from the freeze-fracture preparations (see below).

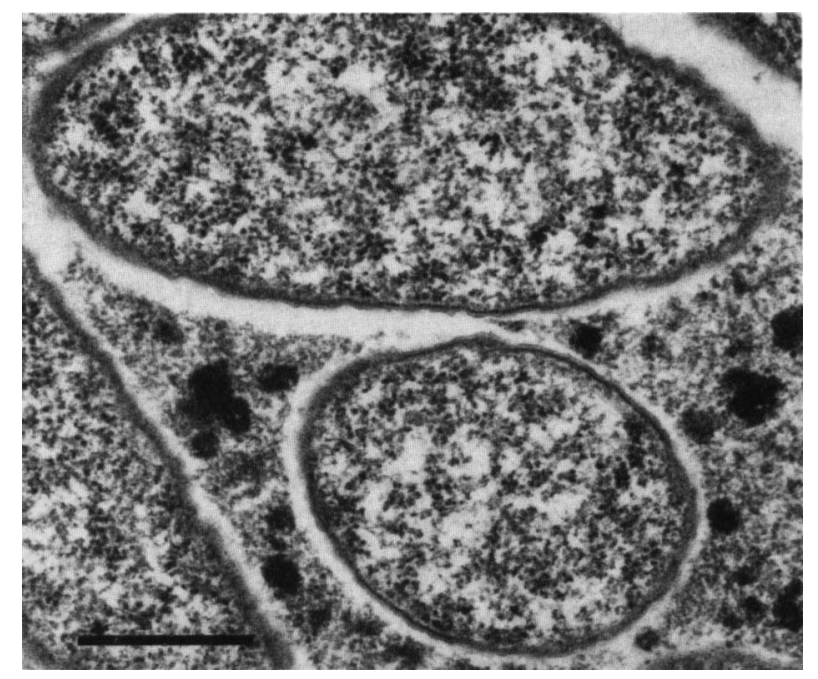

Fig. 1. Electron micrograph of the RF of $H$. obtusa. Bar, $0.5 \mu \mathrm{m}$. 

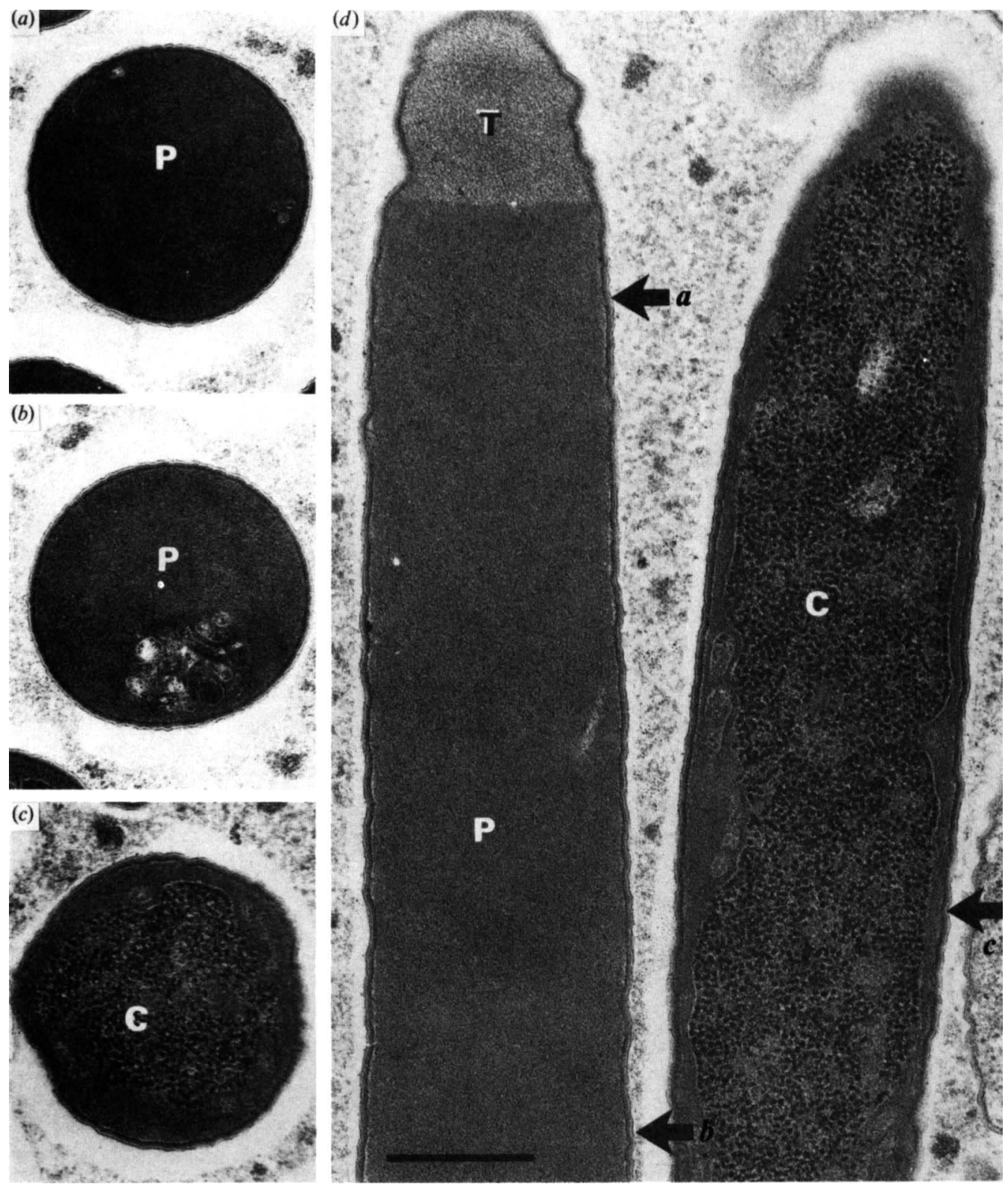

Fig. 2. Electron micrographs of the IF of H. obtusa. ( $a-c)$ Cross-sections of the IF at the levels indicated by arrows in $(d)$, which is a longitudinal section of two IF cells, one with the cytoplasmic part shown, the other with the periplasmic part. $\mathrm{P}$, periplasm with osmiophilic material; $\mathrm{T}$, tip with less osmiophilic material; C, cytoplasm. Bar 0.5 $\mu \mathrm{m}$.

The morphology of the IF of $H$. obtusa differed considerably from that of the RF in that the cell was subdivided into several compartments. One compartment, surrounded by a membrane, contained densely packed granules, presumably ribosomes (Fig. 2). This compartment is assumed to be the condensed bacterial cytoplasm (Gromow et al., 1976; Görtz, 1983). The surrounding membrane must be regarded as the inner bacterial membrane. Between this membrane and the outer membrane the IF contained osmiophilic material, most of which was 

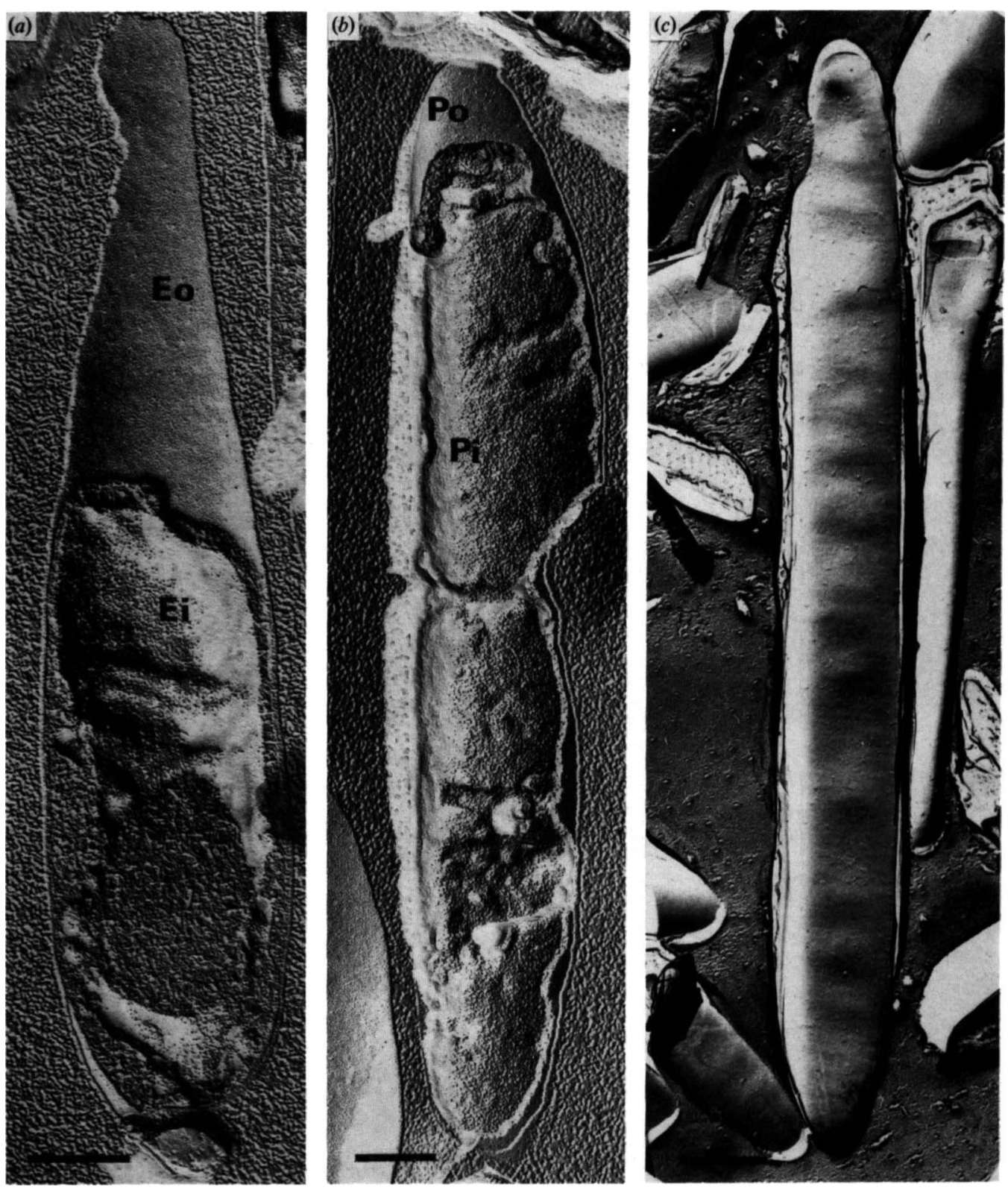

Fig. 3. Freeze-fractures and freeze-etching of the IF. $(a, b)$ Freeze-fractures; bar $0.5 \mu \mathrm{m}$. $(c)$ Freezeetching; bar $1 \mu \mathrm{m}$. Ei, external face of the inner bacterial membrane; Eo, external face of the outer membrane; $\mathrm{Pi}$, protoplasmic face of the inner membrane; Po, protoplasmic face of the outer membrane.

located in one half of the cell (Fig. 2). The polar tip of this half of the cell contained less osmiophilic material (Fig. 2d, compare also Fig. 6), which was not separated from the osmiophilic material by a membrane. One or more thin tubes extending from the main body of the cytoplasm were frequently found to project far into the periplasm, sometimes up to the polar tip. In cross-sections of the IF these tubes were seen as small circles (Fig. 2a). Beneath the outer membrane a dense layer surrounding the osmiophilic material and the less osmiophilic material was visible (Fig. 2). This layer may be regarded as part of the cell wall. 




Fig. 4

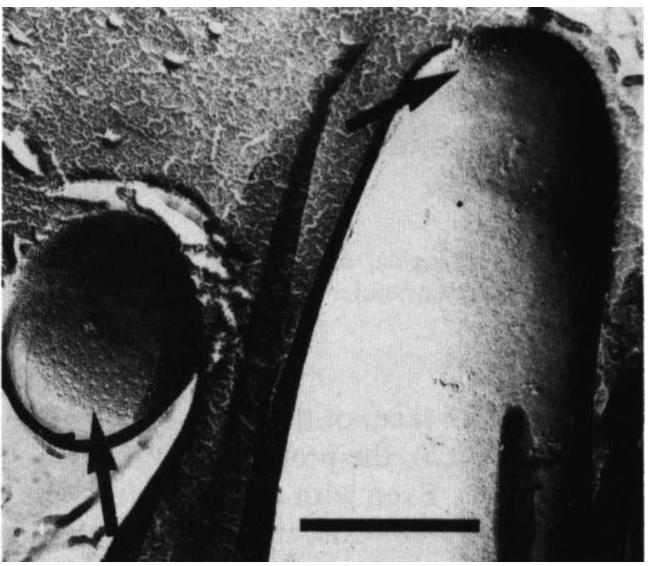

Fig. 5

Fig. 4. Freeze-fracture of the RF. Pi, protoplasmic face of the inner membrane; Po, protoplasmic face of the outer membrane. Bar $0.5 \mu \mathrm{m}$.

Fig. 5. Freeze-etching of the IF. Note the pore-like structures (arrows) which were only found at the pole of the IF. Bar, $0.5 \mu \mathrm{m}$.

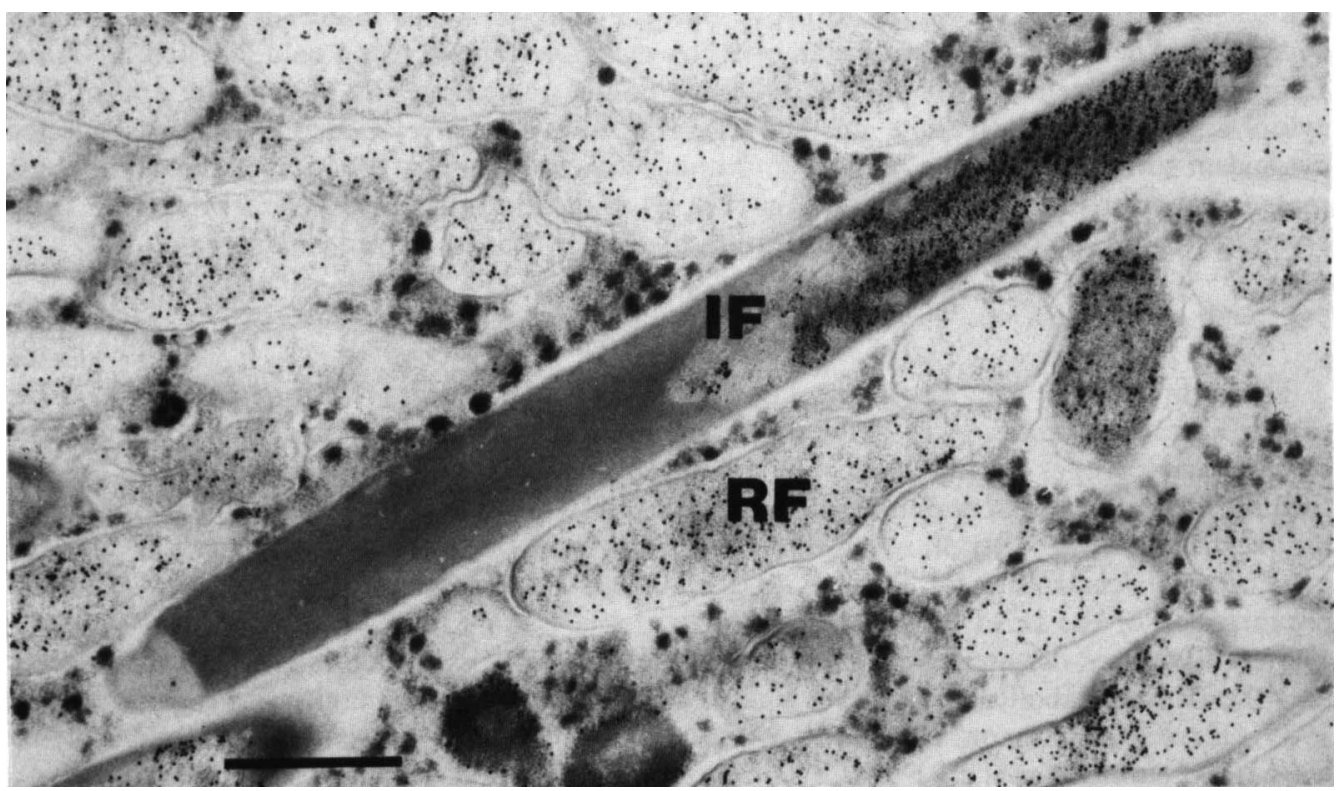

Fig. 6. H. obtusa in the macronucleus of $P$. caudatum treated with gold-labelled RNAase. In the IF, only the compartment encircled by the inner membrane is labelled, indicating the presence of RNA. In the RF, the label is distributed throughout the cell. Unstained section. Bar, $1 \mu \mathrm{m}$.

\section{Freeze-fracture and freeze-etching electron microscopy}

To characterize the membrane layers of the bacteria more precisely, the freeze-fracture technique was used. Freeze-fracture of the outer membrane of the IF of $H$. obtusa revealed that the external face was almost devoid of intramembranous particles (IMPs), and only a few particles were present on the protoplasmic face (Fig. $3 a, b$ ). Also, freeze-etching preparations of the IF exhibited a smooth particle-free external surface (Fig. $3 c$ ). In contrast, the protoplasmic face of the outer membrane of the RF contained high numbers of IMPs (Fig. 4). 


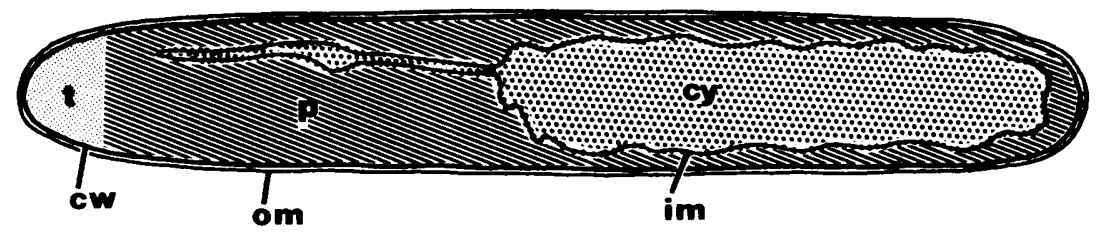

Fig. 7. Cytological organization of the IF of $H$. obtusa. cw, cell wall; cy, cytoplasm; im, inner membrane; om, outer membrane; $p$, osmiophilic periplasm; $t$, less osmiophilic tip.

The fracture faces of the inner membranes of both the RF and IF were studded with many IMPs (Fig. $3 a, b$ ), the protoplasmic faces exhibiting a denser population of particles than the external faces. Even with the freeze-fracture method no membrane could be seen between the osmiophilic material and the less osmiophilic material in the polar tip, thus confirming the thinsection observations. At one pole of the IF, numerous pore-like structures with a diameter of about $12 \mathrm{~nm}$ could be observed (Fig. 5). Replicas of longitudinally oriented IFs showed these pore-like structures only at one end.

\section{Cytochemistry}

Although the observations by conventional electron microscopy and freeze-fracture preparations indicated that the compartment surrounded by the inner membrane is the cytoplasm of the IF, we wanted to prove that the electron-dense material is not part of the cytoplasm. Therefore, the distribution of RNA was investigated using gold-labelled RNAase. Epon-embedded cells clearly showed labelling of the nucleoli of the host nuclei and of host cytoplasmic ribosomes (results not shown). IFs were strongly labelled over the suggested cytoplasm surrounded by the inner membrane. No gold label was found over the osmiophilic material or over the less osmiophilic tip (Fig. 6), indicating that no RNA is present in these compartments. The cytological organization of the IF is summarized in Fig. 7.

\section{DISCUSSION}

The IF and RF represent two stages of the life cycle of $H$. obtusa (Ossipov et al., 1975). The extreme structural differences between the two forms, which are visible with the light and electron microscope, correspond to significant differences of protein patterns between the two forms (Görtz et al., 1988) and indicate the existence of a dramatic type of cellular differentiation unique for bacteria. Ultrathin sections, freeze-fracture, freeze-etching and most clearly the cytochemical localization of RNA with gold-labelled RNAase show the unusual structural organization of the IF of $\boldsymbol{H}$. obtusa.

The differences in outer membrane structure of IF and RF are consistent with the concept that the IF is metabolically inactive, whereas the RF is active and multiplies (Ossipov et al., 1975; Görtz \& Dieckmann, 1980; Gromov \& Ossipov, 1981). The density of IMPs indicates that the outer membrane of the RF is active in the transport of metabolites. The IF, which is also a resting stage (Ossipov et al., 1975; Görtz, 1983), may have little or no transmembrane transport. The IF is resistant to antibiotics, which kill the RF (Görtz \& Dieckmann, 1980; Görtz, 1983). Also, some lytic enzymes, which could digest components of the host chromatin (Görtz, 1983), may be excreted by the RF.

The most remarkable feature of the IF is its huge amount of periplasmic material. Although a number of proteins are located in the periplasm (Görtz et al., 1988; and unpublished), the nature and significance of the periplasmic material are largely unknown. During the infection process the IF always leaves the phagosome and enters the nucleus with the polar tip leading (Görtz, 1983; Fujishima \& Fujita, 1985; Görtz \& Wiemann, 1989). The polar tip is reminiscent of the acrosome of sperm cells or the rhoptries of Plasmodium or other apicomplexa (Görtz \& Wiemann, 1987). The significance of the pore-like structures observed at one pole of the IF is 
unknown, and it remains to be clarified whether these structures are located at the same pole of the IF as the polar tip. Cytological observations suggest that components of periplasmic material are exported at the polar tip during the infection process (Görtz \& Wiemann, 1989).

The authors thank Ms B. Breloh for preparing the sections for transmission electron microscopy. The work was supported by the Deutsche Forschungsgemeinschaft (SFB 310, B 3 and C 2). H. Robenek was supported as a Heisenberg fellow by the Deutsche Forschungsgemeinschaft.

\section{REFERENCES}

Bendayan, M. (1984). Enzyme-gold electron microscopy cytochemistry: a new affinity approach for the ultrastructural localization of macromolecules. Journal of Electron Microscopic Technique 1, 349-372.

FRENS, G. (1973). Controlled nucleation for the regulation of the particle size in monodisperse gold suspensions. Nature, London 241, 20-22.

Fujishima, M. \& Fujita, M. (1985). Infection and maintenance of Holospora obtusa, a macronucleusspecific bacterium of the ciliate Paramecium caudatum. Journal of Cell Science 76, 179-187.

GöRTZ, H.-D. (1983). Endonuclear symbionts in ciliates. In Intracellular Symbiosis, pp. 145-176. Edited by K. W. Jeon. New York: Academic Press.

GöRTZ, H.-D. (1986). Endonucleobiosis in ciliates. International Review of Cytology 102, 169-213.

GöRTZ, H.-D. \& DieckmanN, J. (1980). Life cycle and infectivity of Holospora elegans (Hafkine), a micronucleus-specific symbiont of Paramecium caudatum (Ehrenberg). Protistologica 16, 591-603.

GöRTZ, H.-D. \& WIEMANN, M. (1987). Colonization of the ciliate Stentor multiformis by three different endocytobionts. Endocytobiology and Cell Research 4, $177-184$.

GöRTZ, H.-D. \& WiEManN, M. (1989). Route of infection of the bacteria Holospora elegans and Holospora obtusa into the nuclei of Paramecium caudatum. European Journal of Protistology 24, 101109.

Görtz, H.-D., Freiburg, M. \& WiemanN, M. (1988). Polypeptide differences between infectious and reproductive forms of Holospora obtusa, an endonucleobiotic bacterium from the macronucleus of Paramecium caudatum. Endocytobiology and Cell Research 5, 233-244.

Gromov, B. V. \& Ossipov, D. V. (1981). Holospora (ex Hafkine 1890) nom. rev., a genus of bacteria inhabiting the nuclei of paramecia. International Journal of Systematic Bacteriology 31, 348-352.

Gromov, B. V., MamkaEva, K. A. \& Ossipov, D. V. (1976). Ultrastructure of the I-particles - symbiotic bacteria of the macronucleus of Paramecium caudatum (Protozoa, Ciliata). Izvestija Akademia Nauk SSSR Series Biologiya 3, 399-409.

Moulder, J. W. (1984). Chlamydiales. In Bergey's Manual of Systematic Bacteriology, vol. 1., pp. 729 739. Edited by N. R. Krieg. Baitimore \& London: Williams \& Wilkins.

Ossipov, D. V., SKoblo, I. I. \& RaUtian, M. S. (1975). Iota-particles, macronuclear symbiotic bacteria of ciliate Paramecium caudatum clone M-115. Acta protozoologica 14, 263-280.

Preer, J. R. JR \& Preer, L. B. (1984). Endosymbionts of Protozoa. In Bergey's Manual of Systematic Bacteriology, vol. 1., pp. 795-813. Edited by N. R. Krieg. Baltimore \& London: Williams \& Wilkins. SChmidT, H. J., FreiburG, M. \& GörTZ, H.-D. (1987). Comparison of the infectious forms of two bacterial endonucleobionts, Holospora elegans and $H$. obtusa, from the ciliate Paramecium caudatum. Microbios 49, 189-197. 